Revista Iberoamericana. $\quad$ Vol. LXII, Núm. 175, Abril-Junio 1996; 393-403

\title{
LA ESCRITURA DE LOS CUERPOS EN LA VORÁGINE (LA HISTORIA DE LO INEFABLE)
}

\author{
POR \\ Isabel Alicia Quintana \\ University of California at Berkeley
}

\begin{abstract}
The very fact that a person looking straight forward at her physical image in the mirror or looking down at her own embodied circumference "sees" that she is "not just" and "much more than" a body. Behind the surface of the face in the mirror is blood and bone and tissue but also friends, cities, grandmothers, novels, gods.
\end{abstract}

Elaine Scarry

As long as an individual (the subject) keeps on writing, he is not dead; in fact he is in fine shape, only unpresentable. He authorizes nothing. He lends credibility to no system of verisimilitude. He is just there, as the condition of possibility for his other, the text.

Michel de Certeau

Leer La vorágine en los últimos pliegues de este milenio nos hace, en cierta forma, transitar por algunas de las obsesiones de la literatura latinoamericana de este siglo y parte del siglo XIX. La búsqueda de una esencia, el viaje como retorno a los orígenes, son los temas que recurrentemente aparecen en las obras, aunque, reconceptualizados de modos diversos (desde el Facundo de Sarmiento a Los pasos perdidos de Carpentier). Sin embargo, lo que hace del texto de Rivera una obra "inquietante" es que dichas categorías aparecen de manera problematizada. El viaje que realiza el protagonista, puede afirmarse, es un trayecto en donde se desarticula el paradigma de la novela de la tierra en tanto búsqueda de un modelo de lo nacional (distinto a lo que sucede en Don Segundo Sombra de Ricardo Güiraldes o Doña Bárbara de Rómulo Gallegos).

Sumergido el texto en el diálogo con las escuelas literarias heredadas (romanticismo, realismo, naturalismo y modernismo) avanza, a partir del título mismo, devorándolo todo. En este gesto, a su vez, se produce una distancia paródica que busca desesperadamente elaborar un lenguaje para su objeto textual: la selva y los caucheros. Escribir sobre ella se tornará en la obsesión de Cova, el protagonista de la obra. En una pura proliferación de signos producidos en un medio mórbido, la escritura se escabullirá entre el caucho mismo, blanco, lechoso y mortal. Producirá sus marcas en la corteza de las árboles desangrados. Pero, sobre todo, estallará en los cuerpos de los caucheros. Así, veremos, cómo bajo el recorrido fatal de la sustancia tan codiciada (el caucho), la escritura y los cuerpos se verán amenazados pero, también, irrumpirán violando los espacios del texto perturbando su deseada estabilidad. 


\section{Cortar, CERrar}

La violencia sobre los cuerpos se ejerce de manera despiadada. Ya en el comienzo, Cova asiste a la mutilación de Millán en su enfrentamiento con el toro salvaje (personaje este último que forma parte de la banda de Barrera y que se caracteriza por su destreza en el arte de domar). A partir de allí, el protagonista se obsesionará por la imagen del muerto temiendo la amputación de su cuerpo: "La bóveda del cráneo y las mandíbulas que la siguen faltaban allí, y solamente el maxilar inferior reía ladeado, como burlándose de nosotros" (77). ${ }^{1}$ Más adelante, el Pipa sufre el cercenamiento de sus brazos (Pipa es uno de los personajes que cuenta su relato dentro de la novela y que es rechazado por todos puesto que es un sujeto mentiroso y traicionero, conoce el idioma de los indios y sirve de traductor en el grupo que lidera Cova por la selva). Escena efectista, que calla la voz del dolor. ${ }^{2}$ El cortar, como veremos, produce silencios (es la idea misma de la mutilación, lastimar hasta perder el lenguaje). No existen palabras para expresar tal situación límite, pero tampoco puede el individuo articular su dolor al encontrarse sometido a dicha vejación (el sujeto puede gritar, pero, ni aún su grito se encuentra "representado" en la literatura de Rivera).

Los cuerpos se encuentran amenazados, la mutilación es una imagen que persigue a Cova. Se sueña decapitado como Millán, se alucina con la media mandíbula que le ha quedado al muerto. El silencio de Pipa y el gesto de Millán en su desmembrada mandíbula hacen de la amputación una práctica que lleva a la improductividad del habla. Cortar es, al menos desde una perspectiva psicoanalítica, castrar (la lengua, el sexo). En el corte de los brazos de Pipa se proyecta la voluntad previa de quienes lo hablan amenazado con la pérdida de su sexo. Es precisamente Cova quien lo había rescatado de la mano de sus verdugos, los compañeros del protagonista: "Y yo", afirma Cova, "que pasé de la sorpresa a la caridad, lo conduje en ancas", al Pipa, "con rumbo al hato, entre la protesta de mis compañeros, que lo amenazaban con la castración en represalia de sus fechorías" (77, énfasis mío).

Tras la muerte de Millán, Cova asiste al relato del asesinato de Zubieta. Colgado éste de las muñecas, se cuenta, sus asesinos han ejercido la violencia en el órgano mismo del habla. Todavía vivo, el viejo no puede emitir un sonido impedido por su cruel crucifixión: "balanceábase el vejete, vivo todavía, sin quejarse ni articular, porque en la raíz de la lengua le amarraron un cáñamo" (79, énfasis mío). Hasta aquí, entonces, vemos cómo la violencia de la naturaleza (el toro) y la de los hombres (especialmente en la primera parte enfocada en el mundo de Barrera y sus secuaces) amenaza la integridad de los cuerpos. Las víctimas

\footnotetext{
' Eustasio Rivera, La vorágine (México: Editores Mexicanos Unidos, 1992). Todas las subsiguientes referencias a esta novela corresponden a esta edición.

${ }^{2}$ Elaine Scarry plantea en The Body in Pain que el dolor no tiene un lenguaje para expresarse. El dolor, nos dice la crítica, resiste el lenguaje e, incluso, lo destroza (lleva al ser humano a un estado prelinguístico). En la literatura, agrega Scarry citando a Virginia Woolf, hay una ausencia de la representación literal del dolor. El sufrimiento psicológico tiene su objetivación en la literatura pero no el dolor fisico. Otras disciplinas, la medicina, por ejemplo, han elaborado un lenguaje para "interpretar" el dolor pero nunca es la persona que sufre la que habla (y cuando habla el médico acude al paradigma medicinal para descifrar lo que el otro quiere decir, nunca se le cree lo que el paciente literalmente dice [(Oxford: Oxford University Press, 1987) 5-11]).
} 
han perdido toda posibilidad de objetivar su dolor. El torturador, por su lado, no desea que el otro hable.

Sumido en estas imágenes, Cova las rechaza, pero, al mismo tiempo, las asocia en su delirio de venganza contra su enemigo. Luego de saber que Griselda y Alicia se habían marchado con Barrera, Cova empieza a alucinar: "me parecía ver a Barrera, descabezado como Millán, prendido por los talones a la cola de mi corcel, dispersando miembros en las malezas, hasta que atomizado, se extinguía entre el polvo de los desiertos" (80).

Por un lado, entonces, la fragmentación de los cuerpos. Por el otro la anulación de una facultad, el habla. En este último caso, se renuevan los mecanismos para impedir que el sujeto hable. La tortura, ahora, se ejerce sobre otras zonas: los ojos y los oídos. Un grupo de caucheros que habían conseguido un diario en donde se denunciaban las atrocidades cometidas contra ellos son apresados por sus amos según el relato de Silva. El diseño del castigo pensado para los caucheros no busca "reformar" al individuo sino anular aquella parte del sujeto tornada peligrosa:

Sorprendieron cierta mañana, entre unos palmares de chiquichiqui, a un lector descuidado y a sus oyentes, que no se dieron cuenta del nuevo público que tenían. Al lector le cosieron los párpados con fibras de cumare y a los demás les echaron en los oídos cera caliente (132).

Tras la costura y el derramamiento de cera se clausuran orificios del cuerpo. E1 sujeto es recluido en su interior. Castigo que, a su vez, produce otras anulaciones por extensión ya que, en definitiva, se trata de que los caucheros permanezcan en silencio. Vueltos sobre sí mismos. Ocluidos sus sentidos y facultades, convertidos en herramientas dentro de la gran maquinaria de la explotación industrial cauchera.

\section{RESQUICIOS, RESPIRACIÓN}

Pero, La vorágine no es un texto obturado. Constantemente se producen hendiduras, resquebrajamientos de sentidos $y$, entonces, el texto nos obliga a desleer nuestras primeras lecturas. Los caucheros hacen estallar las costuras. Silva le cuenta a Cova la forma en que ellos, los caucheros, habían resguardado y hecho circular la hoja del periódico: "Recuerdo que la hoja estaba maltrecha, a fuerza de ser leída, y que en el siringal del caño Algodón la remendamos con caucho tibio, para que pudiera viajar de estrada en estrada, oculta entre un cilindro de bambú, que parecía de hachuela" (131). Antes de ser castigados, entonces, los caucheros se han apoderado del caucho para asignarle una función "liberadora". En este caso, remendar (coser) con el propio caucho en un gesto que produce una inversión de sentidos: remendar no es cerrar para no ver sino cerrar para poder leer mediante la preservación de la escritura en el texto. Un paso aun más lejos, los caucheros esconden la hoja y la hacen circular entre los trabajadores en un "cilindro de bambú" que engaña la mirada de los explotadores ("parecía de Hachuela"). La hoja cumple un recorrido en donde de tanto ser leída es destrozada "estaba maltrecha, a fuerza de ser leída", los caucheros han visto y leído y sólo son los últimos a los que se les castiga. El control sobre sus miradas, pues, sigue siendo insuficiente.

La disciplina es ejercida a un nivel rudimentario, mezcla de regímenes diferentes: por un lado, la explotación capitalista, por el otro, un sistema de castigos que responde a la idea 
del "castigo ejemplar". 3 Pero, en medio de la violencia, se filtran espacios abiertos por donde respirar y crear sentidos. No son espacios regalados, sino los que cada uno de los personajes se ha apropiado en su batalla contra los otros y la naturaleza. El que mejor muestra este proceso es el viejo Balbino Jácome quien narra a Silva el trazado de sus maniobras para poder sobrevivir en el infierno de las caucherías. Mintiendo, engañando a unos y a otros Balbino se venga de los explotadores. Aunque la mayoría de los trabajadores cree que es un delator, es precisamente él el que trata de que así lo crean sus amos para poder protegerse y seguir burlándose de ellos. Es Balbino el que descubre los periódicos subversivos y los pone en circulación envolviendo con ellos unos paquetes. Balbino, también, es el que cree que es mucho mejor vivir fuera de la legislación judicial porque sabe que ésta significa aún mayor coerción para los caucheros: "Líbrenos Dios", afirma Balbino, "de que se compruebe crimen alguno, porque los patrones lograrían realizar su mayor deseo: la creación de Alcaldías y de Panópticos, o mejor, la iniquidad dirigida por ellos mismos" (138, énfasis mío).

En esa lucha por irrumpir vemos cómo batallan los cuerpos. Pero, esta vez, no son cuerpos mutilados u obturados. Lo que aparece, por el contrario, es una textualidad corporal que busca ser descifrada. Los cuerpos se convierten en máquinas de sentidos, conglomerados de signos a la espera de un lector. Así, pues, se presenta el viejo Silva (quien a su vez desempeña el oficio de rastreador, lector de la selva). En la mostración de sus úlceras se puede reconstruir su historia y la de los demás caucheros. Cova ve las lastimaduras del anciano e intenta averiguar su origen; Silva le responde: "Son picaduras de sanguijuelas. Por vivir en las ciénagas picando goma, esa maldita plaga nos atosiaga (sic), y mientras el cauchero sangra los árboles, las sanguijuelas los sangran a él" (116). En esta relación encarnizada en donde se sangran mutuamente hombre y naturaleza se produce la marcación de los cuerpos, del hombre y de los árboles. Especie de grafia fundada en la violencia que produce relatos monstruosos.

Por su lado, Silva generará su propia narración en la corteza misma de los árboles; la de la búsqueda de su hijo. En su recorrido deslizará las huellas de su presencia en los troncos. Nuevo relato que circula por debajo de la mirada de los amos. Signos de un "jeroglífico" que se entremezclan con las otras marcas (las hechas por los gomeros para extraer caucho). En su trabajo de ayudante del científico francés ambos (Silva y el naturalista) descubren un árbol en donde confluyen dichos textos:

El árbol castrado ambiguamente por los gomeros, era un siringo enorme, cuya corteza quedó llena de cicatrices, gruesas protuberancias, tumefactas, como lobanillos apretujados.

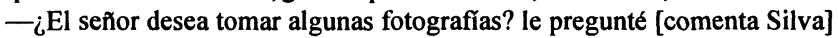

-Sí. Estoy observando unos jeroglíficos.

— ¿Serán amenazas puestas por los caucheros?

\footnotetext{
${ }^{3}$ Michel Foucault, en Vigilar y castigar, retoma las ideas de Jeremy Bentham respecto a la diferencia ideológica que existe en la forma en que los sujetos son castigados antes y después del nacimiento de la prisión. Hasta el siglo XVIII, plantea Foucault, el castigo se ejerce públicamente con la finalidad de prevenir futuros hechos delictivos en la sociedad (actúa como ejemplo). A partir de la prisión, por el contrario, lo que se busca es "reformar" a un sujeto que ha sido individualizado y constituido en sujeto jurídico ante la ley [(México: Siglo Veintiuno Editores, 1985), passim].
} 
-Evidentemente: aquí hay algo como una cruz.

Me acerqué congojoso, reconociendo mi obra de antaño, desfigurada por los repliegues de la corteza: "Aquíestuvo Clemente Silva". Del otro lado, las palabras Lucianito: "Adiós, adiós ...." (130).

A su vez, Silva es portador de otro relato, en su cuerpo lleva la inscripción del amo (los látigos recibidos como castigo). Unainscripción que supone una retórica, la del silenciamiento de la víctima y la de la ejemplaridad, como dijimos anteriormente. Pero, Silva se desnuda y hace que su cuerpo hable ante los ojos sorprendidos del francés:

$\mathrm{Y}$, porque no dudara, lo convencí [dice Silva] objetivamente:

- Seffor diga si mi espalda ha sufrido menos que ese árbol.

Y, levantándome la camisa, le enseñé mis carnes laceradas (130).

El cauchero sabe, pues, que su cuerpo ha de ejercer mayor efecto, "lo convencí objetivamente", afirma, mostrando, así, el control que él posee sobre sus marcas y haciendo que ellas hablen por él. La cámara Kodak plasmará, luego, la crudeza de la imagen: la del hombre pero también la del árbol. El artefacto tecnológico usado "humanitariamente" con la ilusión de que las fotos lleguen a las autoridades: "El árbol y yo", dice Silva, "perpetuamos en la Kodak nuestras heridas que, vertieron por igual amo distintos jugos: siringa y sangre" (130).

Pero, las ilusiones se desvanecen cuando las fotos llegan a las manos del empresario y, allí, la violencia es ejercida nuevamente sobre Silva. Y si los látigos recibidos por Silva habían provocado heridas que hablaban, ahora, la pluma de escribir que el amo le arroja sobre sus espaldas (esto lo hace al comprobar que el viejo había sido fotografiado por el francés para denunciarlos), origina el silencio, al menos, por un momento: "El hombre, requirió la pluma de su escritorio, y, tirándomela de lejos, me la clavó en el omóplato. Todo el cuadril se tiñó de rojo" (131, énfasis mío). Así, en una nueva escena efectista se ha producido una reversión monstruosa de los signos en donde la pluma se ha vuelto un instrumento de tortura (o, tal vez, el signo se ha vuelto visible; la escritura, pues, ha desnudado su finalidad: la letra entra por la sangre).

El relato de Silva se detiene en esta escena y luego seguirá contando otros hechos de su desgraciada peregrinación, pero, allí, el relato se saltea la narrativa del dolor. Los oyentes, entre ellos Cova, deben reconstruir la trama de la historia escuchada partiendo de una ausencia, de lo no dicho (como nosotros, a su vez, lectores de la novela intentamos reconstruir un sentido y, aun, leer las zonas inenarrables del texto). En esta impotencia lingüística el cuerpo toma el lugar de la letra, el signo (no lingüístico) se corporiza creando una nueva densidad textual. Silva, en un nuevo gesto exhibicionista muestra, otra vez, sus heridas. Ante el interrogatorio del Visitador, el viejo sabe que toda palabra ha perdido ya su poder de persuasión, que el habla sólo sirve para diferir lo que él desea expresar. De allí, entonces, que deba recurrir a otra instancia comunicativa. En su cuerpo, el cuerpo de delito (el de los amos, claro), se puede leer la historia de sus padecimientos. Leer las marcas de la tortura, es acceder a un relato que se quiere ocultar: 
Había llegado un Visitador [narra Silva] y en la propia casa recibía declaraciones. Al darle mi nombre, comenzo a filiarme y en presencia de todos me preguntó: ¿usted quiere seguir trabajando aquí?

Aunque he tenido la desgracia de ser tímido, alarmé a la gente con mi respuesta: ¡No señor, no señor!

El letrado acentuó con voz enérgica;

-Puede marcharse cuando le plazca, por orden mía. ¿Cuáles son sus señas particulares? - Éstas afirmé desnudando mi espalda.

El público estaba pálido. El Visitador me acercaba sus espejuelos. Sin preguntarme nada, repitio:

- ¡Puede marcharse mañana mismo! (132, énfasis mío).

El "letrado", sin embargo, no podrá más que "deletrear" las marcas en su sola superficie. Ignora, pues, la historicidad de la que provienen. No sabe distinguirlas (confunde las de la tortura con las que han sido originadas por la naturaleza). De allí, entonces, que, aunque conmovido por las heridas, acepte la versión del relato hecha por el empresario:

${ }_{-}$¿Curiosas cicatrices las de este hombre, verdad? [dice el empresario] ¡Tiene tantos secretos la botánica /.../! No sé si Su Señoría habrá ớdo hablar de un árbol maligno, llamado mariquita por los gomeros. /.../ Dicho árbol, a semejanza de las mujeres de mal vivir, brinda una sombra perfumada; ¡mas ay! del que no resista a la tentación: su cuerpo sale de allí veteado de rojo, con un comezón desesperante, y van apareciendo lamparones que se supuran y luego cicatrizan arrugando la piel. Como este pobre viejo que está presente, muchos siringueros han sucumbido a la inexperiencia (132).

A pesar de su fracaso, Silva ha obligado a que los amos hablen sobre lo que no se debe hablar; los ha forzado a construir una trama sobre sus heridas (historia falsa). De manera que si el castigo intenta fragmentar el cuerpo (como habíamos visto principalmente en la primera parte de este trabajo) o anular sus funciones, bloqueando orificios, cercenando la lengua o lacerando los cuerpos; al mismo tiempo, el cuerpo obliga al otro a que se hable de él. Silva ha transformado la negatividad del signo, convirtiéndolo, pues, en un signo productivo. Las llagas no sólo asombran sino que, además, generan relatos. ${ }^{4}$

\section{ESCRITURA, ENFERMEDAD}

Cova, separado de los otros, aislado en su delirio se transforma en una máquina textual en medio de la selva. A diferencia de los demás, su cuerpo no es un cuerpo marcado. No ha soportado el látigo y, todavía, la selva no ha dejado su huella en él. Sí, se ha desgastado, pero su piel todavía permanece intacta (no hay mención a que las sanguijuelas o insectos hayan dejado su marca sobre él). Sin embargo, su cuerpo ha sido víctima de las terribles batallas generadas por la fiebre. Su corporeidad es una pura apariencia de totalidad. Aunque

\footnotetext{
4 "La tortura reemplaza el lápiz y la hoja por el arma y el cuerpo" postula Michel de Certeau en sus Heterologies [(Minnesota: Minnesota University Press, 1986, 162)]. En un gesto desesperado por lograr articular una protesta Cova, sin embargo, ha transformado su cuerpo en un texto escrito.
} 
no ha sido físicamente mutilado, la enfermedad que por momentos lo invade ha trastornado sus capacidades. Sometido a la parálisis de sus miembros y a la impotencia verbal, Cova se ha convertido en su trayecto por la selva en un sujeto debilitado que va perdiendo el dominio total sobre su cuerpo. Por momentos, entonces, ausente, incapaz de moverse o proferir una palabra; en otros instantes, en cambio, dueño completo de sí mismo e incluso de los otros. Cuando Cova recupera su cuerpo lo utiliza como medio eficaz para conseguir ventajas. Es el momento en que Cova explota sus cualidades de donjuanismo ${ }^{5}$ y las ejerce sobre la no menos corporal Zoraida, la "seductora" y explotadora de los caucheros que habita en la selva. En otras ocasiones, Cova exhibe su dominio sobre el cuerpo de sus compañeros mostrando su internalización de los códigos "selváticos". Cova, pues, castiga con su látigo al Pipa por haberlo desobedecido y, de esta forma, imita el gesto del amo. Así, entonces, el "poeta" se convierte en un sujeto escindido, debido a la enfermedad, y, al mismo tiempo, en un ser dividido al encontrarse sumergido en una situación ambigua respecto del poder (por un lado es jefe de un grupo y como tal da órdenes; por el otro, debe convertirse en cauchero y aceptar el dominio de los empresarios sobre él).

Sometido al rigor de la fiebre, sin embargo, Cova se transforma en un sujeto productivo. Tras el delirio que le provoca la enfermedad Cova comienza a escribir. En su pasaje del llano a la selva, Cova se ha transformado y, en última instancia, ha recuperado su condición: la de escritor. Y es en esta práctica, gesto desesperado, que Cova se apropia (o reapropia) de su espacio de poder inherente: la escritura. Más precisamente, el escritor, entonces, resemantiza lo que para los caucheros constituye la plasmación de su expoliación: el libro de contabilidad. Dice Balbino Jácome al respecto:

Mas el crimen perpetuo no está en las selvas sino en dos libros: en el Diario y en el Mayor. Si su señoría los conociera, encontraría más lectura en del DEBE que en el HABER, ya que a muchos hombres se les lleva la cuenta por simple cálculo, según lo que informan los capataces. Con todo, hallaría datos inicuos: peones que entregan kilos de goma a cinco centavos y reciben franelas a veinte pesos; indios que trabajan hace seis años, $y$ aparecen debiendo aún el mañoco del primer mes; niños que heredan deudas enormes, procedentes del padre que les mataron, de la madre que les forzaron, hasta de las hermanas que les violaron, y que no cubrirán en toda su vida, porque cuando conozcan la pubertad, los solos gastos de su niñez les darán medio siglo de esclavitud (137).

Es, pues, en este cuaderno en donde se ejerce el control de los caucheros que Cova escribirá su historia y la de los gomeros. A través de este uso Cova no sólo subvierte la función a la que están destinados los libros sino que comienza a constituir su objeto textual. En una relación especular entre el cuaderno y la novela (la novela cuenta que había un cuaderno en donde Cova escribía, a su vez, el cuaderno narra la historia de Cova en la selva en la que encuentra un cuaderno en el cual escribe y que dará origen a la novela) se deja entrever la gestación de la trama discursiva de la obra. El texto, pues, se podría decir, es hijo de la selva, se engendra y produce en un medio enfermo. Cova no escribe en el llano, en el terreno salubre sino en la zona putrefacta (Molloy 497) de una naturaleza degradada pero

\footnotetext{
${ }^{5}$ Véase Sylvia Molloy, "Contagio narrativo y la gesticulación retórica en La vorágine", Montserrat Ordónez (comp.), en La vorágine. Textos críticos (Bogotá: Alianza Editora Colombiana, 1987), 504.
} 
también prolífica. La productividad de la escritura está asociada al exceso y a lo monstruoso. Ése parece ser su medio preferido. Tras la fiebre, entonces, se sucede la escritura. Una escritura, que, a su vez, está amenazada con ser devorada. Cova dice escribir para su amigo, quien ha perdido la vista ante los horrores que se producen en las caucherías. Sin vista, ¿cómo es posible que lea? Cova, en verdad, escribe porque como escritor no puede dejar de hacer otra cosa. Creando, de este modo, su propia ficción como novelista. El texto, finalmente, es abandonado a la espera de ser recogido. Allí, solo, conminado por la presencia de una selva devastadora.

\section{VISIÓN, REPRESENTACIÓN}

A medida que Cova va penetrando en la selva su visión se va trastornando. Sus sentidos se confunden y la naturaleza se le presenta como caótica y monstruosa: "Los sentidos humanos equivocan sus facultades: el ojo siente, la espalda ve, la nariz explora" (152). Ya no puede estar seguro de lo que sus ojos observan, por el contrario, su peregrinar se convierte en un deambular entre objetos deformes. Pero, como vimos, al mismo tiempo, es en la selva donde empieza a escribir, como si la fiebre que produce este extrañamiento, este trastrocamiento de los sentidos, alentara su escritura. Sumido en un mundo ya no sólo visual, sino plagado de sonidos y olores Cova iniciará la narrativa de su propio viaje. En una especie de rapto dionisíaco en donde a partir de la ebullición de las sensaciones y la confusión perceptual, el artista recupera su función. ${ }^{6}$ El texto, así, nace en el terreno de la proliferación de sentidos. El ojo ha sido abandonado y, ahora, el cuerpo ha recuperado otras zonas para descubrir el mundo de la selva. ${ }^{7}$

Pero, cuando Cova narra su peregrinación debe escribir, entre otras cosas, sobre el cuerpo de los otros. Allí, entonces, las imágenes se fragmentan (habíamos visto cómo se describe la atomización de los cuerpos mutilados) en función de buscar un efecto. Especie

\footnotetext{
${ }^{6}$ Martin Jay, plantea, cómo en contraposición a la visión positivista representada por los impresionistas y naturalistas a nivel estético surgen críticas a esta postura en las filosofias de Nietzsche y Bergson (aproximadamente hacia la época en que Rivera escribe esta novela). Para el primero, la visión era una actividad más proyectiva que receptiva. La fuerza dionisíaca, pues, consistía, en términos cognitivos, en "la irrupción de la insistente voz de los instintos de vida afirmativos" sobre "el ideal de neutralidad observacional y especulativo" [Downcast Eyes (Berkeley: California University Press, 1993), 191]. Bergson, agrega Jay, criticaba la "tiranía" de la visión en nombre de una recuperación de lo corporal. La forma de conocer, para Bergson, era a través de la experiencia del cuerpo. Éste ya no era visto como objeto puro de contemplación sino como un vehículo existencial, portador de la elección humana (Jay 193).

${ }^{7}$ En su análisis sobre Michel Certeau, Luce Giard plantea que para este filósofo existe una relación profunda entre la experiencia del viaje y la visión. La posesión del objeto a través de la visión es lo que definiría para Certeau el conocimiento moderno. La visión, afirma Giard citando a Maurice Merleau-Ponty, cautiva nuestra visión porque es no sólo el viaje hacia objetos externos sino que es un retorno a la realidad de origen, "viajar es ver" pero, a su vez, el ver ya constituye un viaje ["Michel de Certeau's Heterology and the New World", en New World Encounters (Berkeley: California University Press, 1993), 316-17). En nuestro trabajo, en cambio, observamos, cómo se plantea una crisis de este punto de vista. Para Cova ya no es posible confiar en la visión, por el contrario, la vista puede engañar.
} 
de mirada "impresionista" que captura un instante y lo fija borrando la historicidad. ${ }^{8}$ Es el gesto, pues, que realiza también el científico con su cámara. Distanciado de su objeto y parcelándolo. Borrando la continuidad. ${ }^{?}$

De allí en adelante [comenta Silva], el lente fotográfico se dio a funcionar entre la peonada, reproduciendo fases de la tortura, sin tregua, ni disimulo, abochornando a los capataces, aunque mis advertencias no cesaban de predicarle al naturalista el grave peligro de que mis amos lo supieran. El sabio seguía impertérrito, fotografiando mutilaciones y cicatrices (130, énfasis mío).

El "naturalista", pues, con su ojo fotográfico sólo puede reproducir "fases de la tortura". La anterioridad o el instante que se produce entre el suceder de las fases no puede ser capturado. Lo que se plantea, de este modo, es la imposibilidad de la representación total. La sucesión temporal se fragmenta ante su objeto. ${ }^{10}$ Sin embargo, la fotografía de la tortura, más allá de la representación del objeto, produce un efecto sobre la recepción cuya primera sintomatología es la muerte del lenguaje, el trauma. En él, tal vez, puede decirse que la fotografía recupera una dimensión presimbólica, un estado anterior que afecta directamente las emociones. ${ }^{11}$

\section{PATERnidAd, ESTERILIDAD}

La selva, por su lado, se presenta como inmensamente femenina, devoradora, insaciable en su apetito. Todo organismo vivo se encuentra amenazado de caer bajo sus garras: "Aquí,

\footnotetext{
${ }^{8}$ Esta forma de representación puede ser vista como dentro de los legados de la novela naturalista. Respecto a esta escuela afirma Jay: "Tanto la novela naturalista de Zolá, que pretende seguir los principios de la fisiología positivista de Claude Bernard y que busca reemplazar la novela de imaginación por la de observación y experimentación, como los impresionistas en pintura, privilegian su visión sobre la superficie aparente de las cosas en lugar de una mirada penetrante sobre la profundidad de las estructuras preferidas por los realistas" (Jay 173).

${ }^{9}$ La sintaxis de la fotografía, señala Jay, es la sintaxis de lo inmediato, de la percepción sinóptica y discontinua, de lo singular y contingente contrario a lo universal y estable (Jay 139).

${ }^{10}$ Henry Bergson observa cómo la imagen cinematográfica produce un conocimiento fragmentado: "Nuestra actividad va de una composición a otra, imprimiéndole cada vez una nueva sacudida al caleidoscopio, pero sin interesarse por las sacudidas y sin ver más que la nueva figura" [La evolución creadora (Barcelona: Planeta, 1980), 267]. El tiempo "conceptual" es, para el filósofo, el que congela los procesos y los abstrae. Una forma de conocimiento mediatizado, puesto que lo verdaderamente "real" es imprevisible e incognoscible en su devenir.

"Para Barthes, según Jay, la estructura de la fotografia se desarrolla en dos niveles. Un nivel denotativo que consiste en la capacidad de imitar los objetos, la imagen no es la realidad pero es su perfecto análogo (de allí, su "efecto de lo real"). Por otro lado el connotativo, es decir, las resonancias culturales generadas por su recepción. Según Barthes, afirma Jay, la fotografía puede en verdad convertirse en un auténtico simulacro del mundo en un caso particular (una experiencia no mediada por códigos culturales): los acontecimientos traumáticos porque "el trauma es una suspensión del lenguaje, el bloqueo del significado" [Roland Barthes, "The Reality Effect", The Rutle of Language (Berkeley: California University Press, 1989) 146; (citado en Martin Jay, Downcast Eyes, cap. VIII, 442)].
} 
la parásita afrodisíaca que llena el suelo de abejas muertas; la diversidad de flores inmundas que se contraen con sexuales palpitaciones y su olor pegajoso emborracha como una droga" (151). Pululan las descripciones de las enredaderas que atrapan a sus víctimas, las arañas que tejen su tela también para cazar a sus presas, los caribes y hormigas que en instantes consumen la carne. Un ambiente profundamente sexuado en donde la naturaleza voraz va engulléndose en el mismo instante en que se reproduce, estableciendo, así, una relación perversa y obscena con ella misma.

La selva, también, es el lugar en donde se trafican los cuerpos, se los prostituye. Las niñas son entregadas por sus padres a los empresarios a cambio de sal u otras mercancías. Zoraida, a su vez, se presenta como la misma selva: hambrienta y amenazadora. Por su lado, Cova, aunque también habrá de caer en las garras de la madona, su sexualidad parece haber sido ya previamente desgarrada. Apenas entra en la selva, Cova reflexiona sobre Alicia (quien ya se encontraba embarazada cuando se separan): “¿Y yo por qué me lamentaba como un eunuco?" (86, énfasis mío). La pérdida de su mujer, en verdad, se presenta como la pérdida simbólica de su virilidad y el trayecto hacia la selva, quizá, como el intento de recuperación de la misma. En su relación con Zoraida parece, entonces, readquirir su sexualidad, una sexualidad pura, instintiva, pero vacía de toda idea de productividad. En verdad, la paternidad de Cova se desarrolla en la selva a nivel intelectual; la producción de su texto. Su hijo, en cambio, ha sido concebido en los llanos.

Por su lado, el hijo de Silva se ha suicidado en la selva. Su padre lleva consigo sus huesos, elemento final de un cuerpo traspasado por la angustia de la explotación. Muerto, terminado, sólo queda de él la zona más improductiva del cuerpo, lo que ya no puede regenerarse (la sangre, la piel, pueden, por ejemplo, reproducirse). Cova y su hijo son, al final, también "devorados" por la selva. De modo que, en este espacio de la máxima reproductividad orgánica, sin embargo, se produce la mortandad filial. La fallida paternidad de Cova, pues, se resuelve a nivel textual. Lo que queda de él es, entonces, sólo su libro.

La huida de Cova a la selva se puede leer como la desarticulación del viaje de Favio a las pampas en Don Segundo Sombra o el de Santos Luzardo en Doña Bárbara. En La vorágine, no hay espacio para los hijos ni tampoco lugar para salidas conciliadoras. El texto trastoca los esencialismos (el gaucho pacificado en la imagen de Don Segundo Sombra, por ejemplo) y pulveriza las dicotomías. La civilización (la industria cauchera) no se contrapone a la barbarie (la selva), ni la selva (para "salvar" a su hijo Cova debe penetrar aun más en la selva), a su vez, a la ciudad. La escritura, por su parte, se ha generado en el crudo espacio de la violencia y no en el recinto sagrado de la urbe. Al final, pues, el poeta se retira, dejándonos la perturbadora sensación de que su autor ha desaparecido (por supuesto que todos sabemos que es Rivera quien controla el relato). En tal ambigüedad, en donde se suspende la clausura del texto (no se sabe si Cova y su familia viven o han muerto) surge la máxima incertidumbre. El "autor" (Cova) se ha retirado pero su ausencia no es total. Algunos, incluso creen poder rescatarlo de las espesuras de la selva (nos referimos, aquí, a las expediciones realizadas para rescatarlo, el "efecto de lo real" parece haberse producido en determinado contexto de la recepción).

De esta forma, el producto último es la ficción de un texto puro que habla (sin padre), un texto anómalo, enfermo, en el cual por momentos el lenguaje ha sufrido desplazamientos e inversiones y ha hablado por otros signos. El signo lingüístico, vimos desde el comienzo, 
se ha tornado, en la selva, insuficiente para narrar la historia de la violencia. Se ha enmudecido (¿cómo puede el texto no hablar?), ha callado relatos pero, al mismo tiempo, ha estallado en otros signos, otros cuerpos. Así, la novela se ha tornado, seguramente sin quererlo, en la historia de lo inefable, lo que no se puede narrar: el dolor humano. Convirtiéndose, de este modo, en un texto indigerible que asecha la ansiada paz de los "jardines versallescos". ${ }^{12}$

${ }^{12}$ En una distancia paródica en relación a los modernistas Cova escribe sumido en la angustiosa presencia de la selva: “ ¡Nada de risueñores enamorados, nada de jardín versallesco ...” (La vorágine, 151). 
